\title{
Antimicrobial Resistance in the Asia Pacific region: a meeting report
}

\author{
Esabelle Lo Yan Yam ${ }^{1 *}$ (D), Li Yang Hsu², Eric Peng-Huat Yap ${ }^{1}$, Tsin Wen Yeo ${ }^{1}$, Vernon Lee ${ }^{2,3}$, Joergen Schlundt ${ }^{4}$, \\ May O. Lwin ${ }^{5}$, Direk Limmathurotsakul ${ }^{6,7}$, Mark Jit ${ }^{8,9,10}$, Peter Dedon ${ }^{11,12}$, Paul Turner ${ }^{13,14}$ and \\ Annelies Wilder-Smith ${ }^{1,15,16^{*}}$
}

\begin{abstract}
The Asia Pacific region, home to two-thirds of the world's population and ten of the least developed countries, is considered a regional hot-spot for the emergence and spread of antimicrobial resistance (AMR). Despite this, there is a dearth of high-quality regional data on the extent of AMR. Recognising the urgency to close this gap, Singapore organised a meeting to discuss the problems in the region and frame a call for action. Representatives from across the region and beyond attended the meeting on the "Antimicrobial Resistance in the Asia Pacific \& its impact on Singapore" held in November 2018. This meeting report is a summary of the discussions on the challenges and progress in surveillance, drivers and levers of AMR emergence, and the promising innovations and technologies that could be used to combat the increasing threat of AMR in the region. Enhanced surveillance and research to provide improved evidence-based strategies and policies are needed. The major themes that emerged for an action plan are working towards a tailored solution for the region by harnessing the One Health approach, enhancing inter-country collaborations, and collaboratively leverage upon new emerging technologies. A regionally coordinated effort that is target-driven, sustainable and builds on a framework facilitating communication and governance will strengthen the fight against AMR in the Asia Pacific region.
\end{abstract}

Keywords: Asia Pacific, Singapore, One Health, Global Health, Global Mobility, Travel, Drug Resistance, Antimicrobial Resistance

\section{Introduction}

Antibiotics have revolutionised modern medicine and facilitated advances in transplantation, chemotherapy and surgery, while drastically reducing the mortality and morbidity from infectious diseases. The ever-increasing demand for antibiotics in healthcare is evident in the $65 \%$ increase in global consumption from 21.1 billion to 34.8 billion daily doses from 2000 to 2015 [1]. Besides human healthcare, antibiotics are used for the prevention and treatment of diseases in food-producing animals in the agriculture and aquaculture industries, as well as for growth promotion. Medically-important antibiotics accounted for $51 \%$ of all domestic sales of antibiotics approved for food-producing animals in the United States (US) in 2017 [2]. The widespread use of antimicrobials has hastened the development

\footnotetext{
* Correspondence: esabelleyam@gmail.com; awilder-smith@ntu.edu.sg ${ }^{1}$ Centre for Global Health, Lee Kong Chian School of Medicine, Nanyang Technological University, 11 Mandalay Road, Singapore 308232, Singapore Full list of author information is available at the end of the article
}

of antimicrobial resistance (AMR) through increased selection pressure for genes that confer mechanisms to reduce the effectiveness of antibiotics. This led to the emergence of multi (MDR) and extensively drug-resistant (XDR) pathogens such as Mycobacterium tuberculosis (MTB), carbapenem-resistant Enterobacteriaceae (CRE), XDR Pseudomonas aeruginosa and Acinetobacter baumannii and methicillin-resistant Staphylococcus aureus (MRSA). These pathogens are part of the World Health Organisation (WHO)'s priority list published in 2017, widely known as the "dirty dozen" that pose a significant threat to human health [3]. Recognising the potential scale and enormity of the impact of AMR, the Heads of States at the United Nations General Assembly passed a resolution in September 2016 to reaffirm their commitment to tackling the rising threats of AMR [4].

The Asia Pacific region (APAC), home to two-thirds of the world's population and ten of the least developed countries $[5,6]$, is highly vulnerable to the threats of AMR. 
AMR undermines efforts in improving the health systems and health security in APAC and threatens the overall growth potential of the region. In light of the growing threat of AMR in the region, Lee Kong Chian School of Medicine (LKCMedicine) together with Saw Swee Hock School of Public Health; Singapore-MIT Alliance for Research and Technology; National Centre for Infectious Diseases; DSO National Laboratories; and the Ministry of Health, Singapore organised a meeting titled "Antimicrobial Resistance (AMR) in the Asia Pacific \& its impact on Singapore". The meeting was held from 13 to 14 November 2018 at the LKCMedicine in Singapore to coincide with the annual World Antibiotic Awareness Week.

This report summarises the information and insights shared by 26 experts who represented the academic, industry and government sectors from Papua New Guinea, Timor Leste, Indonesia, Thailand, Cambodia, Myanmar, India, Singapore, US and the United Kingdom. This report consists of three sections, namely, the challenges and progress in surveillance, drivers and levers of AMR, and potential innovations and technologies to combat the increasing threat in the region. We will present potential solutions and a roadmap as discussed during the meeting.

\section{Global antimicrobial resistance}

Drug-resistant pathogens have been found in every continent; however, differences between countries in the prevalence of AMR depend on multiple factors including levels of antibiotic consumption, access to clean water, adequate sanitation, vaccination coverage, the availability of quality healthcare, and access to high-quality medical products. Increasing international travel has played a key role in the spread of drug-resistant pathogens including but not limited to MRSA and extended spectrum beta-lactamase (ESBL) producing Enterobacteriaceae [7-9], increased the proportion of drug-resistant enteric pathogens causing travellers' diarrhoea [10-24], and generally increased the number of travellers infected by drug-resistant pathogens [25, 26]. Globally, third-generation cephalosporin-resistant Escherichia coli and Klebsiella pneumonia were estimated to cause 3.7 million to 6.4 million bloodstream infections, and 28.9 million to 50.1 million serious infections, and carbapenem-resistant strains caused 0.4 to 0.5 million bloodstream infections, and 2.7 to 3.1 million serious infections in 2014 [27]. In the European Economic Area, five drug-resistant bacterial infections accounted for an estimate of 33,110 attributable deaths and 170 DALYs per 100,000 population in 2015 , rivalling the combined burden of influenza, tuberculosis and HIV [28]. These numbers foreshadow the long-term projected consequences of 10 million deaths annually and an additional 24 million people forced into extreme poverty by 2030 if no action is taken against AMR [29-31].
Antimicrobial resistance in the Asia and Pacific

Asia Pacific is highly vulnerable to the threats of AMR. The challenges that impede the progress in controlling AMR in APAC are wide-ranging and affect both the low-to-middleincome countries (LMICs) and high-income countries. The region is projected to be home to 27 of the world's 43 megacities by 2030 [32], and these densely populated cities may serve as huge reservoirs for the spread of drugresistant pathogens. This holds particularly true for LMICs with unplanned urbanisation, creating environments where sanitation is poor, wastewater management is suboptimal, and where air pollution causes respiratory conditions that are often mistakenly treated with antibiotics $[1,32,33]$. Within the region, the WHO South-East Asia (SEA) countries were postulated to have the highest risk of emergence and spread of AMR among all WHO regions [34-36], for which the highly transferable New Delhi metallo- $\beta$ lactamase-1 (NDM-1) is a relatively recent reminder [37]. At the same time, the region grapples with a high incidence of infectious diseases. China and India alone account for almost one-third of the global incidence of rifampicinresistant TB. This number does not include yet another one-third of people infected with TB that are either undetected or not captured by national statistics [38]. Patients in 10 hospitals across India with MDR and XDR bacteria were 1.57 times and 2.65 times more likely to die as compared to similar susceptible infections [39]. In Thailand, 19, 122 of 45,209 (43\%) deaths in nine hospitals across Thailand were attributed to healthcare-associated infections due to multi-drug resistance [40].

\section{Antimicrobial Resistance Surveillance Progress and Challenges}

The WHO Global AMR Surveillance System (GLASS) and Organisation for Animal Health (OIE) global database on the use of antibiotics in animals were established to enable the systematic collection of data globally. By 2018, 9 of 11 WHO SEA region countries and 6 of 27 Western Pacific Region countries had enrolled into GLASS, but reporting of surveillance data is limited [41]. Complementing the functions of GLASS and OIE in other parts of the world are successful regional AMR surveillance networks such as the European Antimicrobial Resistance Surveillance Network (EARS-Net), Central Asian and Eastern European Surveillance of Antimicrobial Resistance (CAESAR) and Red Latinoamericana de Vigilancia de la Resistencia a los Antimicrobianos (ReLAVRA) [42].

Although several networks collect data on selected pathogens in the region, there are no formal surveillance networks dedicated to AMR in APAC [43]. The lack of standardised and consistent data collection and reporting processes in APAC signifies a massive gap in the ability to reliably determine the burden of AMR and impact of interventions implemented in the region $[43,44]$. The 
generation of high-quality data is even more challenging, particularly in settings with limited laboratory infrastructure. In these settings, clinicians frequently prescribe antibiotics without the support of microbiological results and diagnostic specimens are mostly submitted from patients in whom empiric treatments have failed [45], leading to the generation of small datasets with an over-representation of AMR isolates. Empirical therapy is practised even in large "tertiary" hospitals, where the "culture of culturing" among clinicians is frequently lacking [46]. Also, laboratory procedures and quality assurance may be suboptimal due to noncompliance to quality control testing recommendations, resulting in the production of poor quality data $[47,48]$.

Nonetheless, many efforts have been made to improve the situation. At the regional level, the commitment to address AMR was demonstrated by the inclusion of AMR in the current Association of Southeast Asian Nations (ASEAN) five-year work programme (2016-2020). The signing of the Joint Declaration on Action against AMR by the Heads of States in 2017 and the ASEAN Plus Three Leaders' Statement on Cooperation against AMR (ASEAN Plus Three are the People's Republic of China, Japan and Republic of Korea) in 2018 have also sent a clear signal on the recognition of a need for regional collaboration against AMR. Based on the 2017 Joint Declaration, the Philippines, with input from the other ASEAN Member States is preparing a draft Strategic Framework that will guide the ASEAN member states in planning for AMR control. The Strategic Framework is targeted to be endorsed by the ASEAN Health Ministers in the near future and will be followed up by a monitoring \& evaluation framework for progress tracking.

At the national level, countries are making progress, albeit at varying pace. Timor Leste, a country that has emerged from a period of political instability and war in recent years, is at the start of the process in establishing a surveillance system to understand the impact of AMR in the country. Although the country's past has been characterised by weak microbiology laboratory capacity and scarcity of data, the Timorese National Health System has made many efforts in the past few years to improve infrastructure and human resources in microbiology diagnostics and bring together the relevant stakeholders to implement a multi-centric surveillance system by 2019. The progress thus far includes the introduction of antimicrobial susceptibility testing for clinical bacteria isolates and a closer working relationship between the Laboratorio Nacional de Saude and National Hospital to incorporate microbiology diagnostics into daily clinical decisions as well as to capture trends of infections and AMR [49]. The collaboration has also generated early evidence indicative of more widespread Gram-negative bacteria AMR in Timor Leste [50].

In contrast, Indonesia, the fourth most populous country in the world, is transitioning from the early phase of its efforts against AMR that started in 2017. Guidelines for surveillance have been developed but not fully implemented across the country, and quality data and analyses are far and few [51]. Nonetheless, the country is in the process of nominating a National Reference Laboratory (NRL) and National Coordinating Centre under the leadership of the Committee of AMR Control. So far, the committee has performed several surveys for ESBL- producing $E$. coli and $K$. pneumonia and other pathogens from blood and urine specimens, and antimicrobial usage (AMU) from hospital prescription in 2016 and 2017. There are opportunities for capacity building through the establishment of external quality assurance and proficiency test in the NRL, and extension of the surveys to the broader network of hospitals including 20 national and province-level referral hospitals, and 100 regional-level referral hospitals. It was also highlighted that the development of guidelines and tools for prescription review would help to raise awareness of AMR and guide decision making to reduce the rate of empirical therapy in Indonesia.

In addition to strengthening AMR surveillance for human health, countries such as Myanmar and Singapore are making progress in incorporating a multisectoral approach in tackling AMR. In Singapore, the National Strategic Action Plan overseen by the AMR Coordinating Office emphasises a One Health approach for education and training, surveillance and risk assessment, and research. In Myanmar, a multisectoral approach combining the expertise of epidemiologists, infectious disease clinicians and social scientists to perform research studies and facilitate translation of evidence to policy for AMR is underway.

\section{Opportunities for antimicrobial resistance surveillance in the Asia and Pacific}

There are several opportunities to improve the capacity for AMR surveillance in the region as a result of new funding streams and technological breakthroughs, building on the foundation laid by past efforts in respective countries and commitment by international and regional bodies. This section briefly covers the potential of technology such as whole-genome sequencing (WGS) before a more extensive discussion on technology in the last section on Innovations

\section{to Fight Antimicrobial Resistance.}

New funding streams such as the Fleming Fund aim to collate existing AMR data from the laboratories in the region and work prospectively in Indonesia, Laos, Papua New Guinea, Timor-Leste, and Vietnam to build human and laboratory capacity in order to facilitate WHO GLASS data submission [52]. It will augment prior and existing efforts by organisations such as the Wellcome Trust which is supporting many research programmes on AMR in the region, including the development of methods to improve the calculation of drug-resistant infection mortality. Two such methods include: 
- The "AutoMated tool for Antimicrobial resistance Surveillance System" (AMASS) application to enable local hospitals to perform data analysis, generate report and share data [53].

- A patient-focused surveillance tool through the "A Clinically-Oriented antimicrobial Resistance surveillance Network" (ACORN) to supplement existing pathogen-focused surveillance systems.

On the technology front, the increasing affordability of WGS presents an opportunity to enhance surveillance efforts by using molecular epidemiology data to map out the evolution, spread and transmission of antibiotic-resistant genes and drug-resistant pathogens. Previous studies that used WGS on K. pneumoniae and Shigellae spp. [54, 55] showed that real-time genetic characterisation could be incorporated into current surveillance programmes to investigate, inform and potentially intervene during outbreaks. These studies have paved the way for the use of WGS on other drug-resistant pathogens such as CRE [56]. Work in this area has been initiated by research groups in Singapore who performed WGS on clinical and surveillance CRE isolates collected from 6 public hospitals and the results have revealed diverse strain types and transmission clusters in Singapore. It also demonstrated the potential to apply WGS to investigate the contribution of plasmids and bacterial strains separately to the transmission of CRE through potential reservoirs, as well as generate molecular data to support conventional epidemiological investigations [57].

Using a One Health approach, samples could be collected from farm to market/restaurant and sequenced to gain insights into the transmission of drug-resistant genes and bacteria from live animals to meat and cooked food, and thus further understand the ecological drivers of AMR. The projects involving WGS will require considerable IT infrastructural investment to process, store and handle a large amount of data; develop cloud-based solutions and visual interface for data sharing; and statistical and bioinformatics expertise for data analysis. It also currently faces challenges in not having an international standardised protocol for sample and data processing, dedicated funding and personnel, and consensus for open communication as well as sharing of samples and data within and beyond countries.

Lastly, building on efforts within countries and acknowledgement of the importance of collaboration with international and regional bodies, stakeholders and policymakers should consider forming a dedicated organisation like a regional Centre for Disease Control and Prevention (CDC). The significant progress achieved by the European $\mathrm{CDC}$ and African $\mathrm{CDC}$, including the organisation of the EARS-Net and European Surveillance of Veterinary Antimicrobial Consumption (ESVAC), and launch of the AMR framework to direct efforts and resources to the threats of AMR in Africa, are exemplary of successful regionally coordinated efforts $[58,59]$. While signs of progress have been encouraging, the data collection process in APAC could be better coordinated to ensure a comprehensive evaluation of the impact and status of AMR in the region $[41,60]$. A regional CDC could provide the focal point to facilitate, support and elevate the AMR agenda above the national level, and help countries to achieve global health targets more effectively.

Box 1 Issues, recommendations and target outcomes to improve surveillance on AMR in the APAC

\begin{tabular}{|c|c|c|}
\hline Issues & Recommendations & Target Outcomes \\
\hline $\begin{array}{l}\text { Weak health } \\
\text { systems }\end{array}$ & $\begin{array}{l}\text { - Increase country } \\
\text { capability and capacity } \\
\text { to reliably detect the } \\
\text { priority pathogens, and } \\
\text { link laboratory results to } \\
\text { clinical outcome. } \\
\text { - Prescribe microbiological } \\
\text { culture (particularly, } \\
\text { blood and urine) } \\
\text { appropriately. } \\
\text { - Report case-based sur- } \\
\text { veillance report, together } \\
\text { with evaluating attribut- } \\
\text { able mortality rate for } \\
\text { AMR. }\end{array}$ & $\begin{array}{l}\text { Improved capacity and } \\
\text { capability to diagnose, } \\
\text { treat and prevent AMR at } \\
\text { all levels of the health } \\
\text { system. }\end{array}$ \\
\hline $\begin{array}{l}\text { Unclear burden } \\
\text { of AMR }\end{array}$ & $\begin{array}{l}\text { - Improve surveillance to } \\
\text { better describe the } \\
\text { burden of AMR. } \\
\text { - Better capture and } \\
\text { report records of deaths } \\
\text { and other clinical } \\
\text { outcomes attributable to } \\
\text { AMR. } \\
\text { - Develop robust models } \\
\text { that are practical and } \\
\text { acceptable to } \\
\text { policymakers and } \\
\text { healthcare providers. }\end{array}$ & $\begin{array}{l}\text { Ability to monitor and } \\
\text { evaluate the effects of } \\
\text { interventions, and project } \\
\text { the impact of AMR using } \\
\text { modelling options. }\end{array}$ \\
\hline $\begin{array}{l}\text { Lack of formal } \\
\text { network to } \\
\text { address AMR }\end{array}$ & $\begin{array}{l}\text { - Engage policymakers to } \\
\text { consider developing an } \\
\text { official network for AMR } \\
\text { in the region, based on } \\
\text { role models developed } \\
\text { by European CDC, } \\
\text { African CDC and } \\
\text { European Medicines } \\
\text { Agency, such as EARS- } \\
\text { NET and ESVAC. }\end{array}$ & $\begin{array}{l}\text { Consolidation of resources } \\
\text { and efforts across } \\
\text { countries to deliver } \\
\text { impactful programme at } \\
\text { the regional level. }\end{array}$ \\
\hline $\begin{array}{l}\text { Lack of open- } \\
\text { access data for } \\
\text { global sharing }\end{array}$ & $\begin{array}{l}\text { - Engage with } \\
\text { policymakers to make } \\
\text { data open-access, such } \\
\text { as AMU and AMR sur- } \\
\text { veillance data. } \\
\text { - Improve the } \\
\text { understanding and } \\
\text { utilisation of all } \\
\text { surveillance data to } \\
\text { decide on resource } \\
\text { allocation for } \\
\text { interventions and to } \\
\text { inform the } \\
\text { implementation of } \\
\text { action plans. }\end{array}$ & $\begin{array}{l}\text { Robust and reliable data } \\
\text { to support further policy } \\
\text { engagement, monitoring } \\
\text { and evaluating impact of } \\
\text { interventions, and } \\
\text { research and } \\
\text { development. }\end{array}$ \\
\hline
\end{tabular}




\section{Drivers and Levers of Antimicrobial Resistance in the Asia and Pacific}

The emerging economies and growing prosperity in APAC will likely exacerbate the trend of AMR. The growth in wealth may lead to an increase in demand for animal protein and the shift to large-scale farming in countries such as China and India which are projected to double antibiotic consumption by 2030 [61]. This trend will be compounded by an increase in purchasing power and access to antibiotics, including new and second-line antibiotics that are expensive [1, 62]. Furthermore, travel to and from APAC is increasing rapidly [63] associated with an increasing influx of drug-resistant pathogens [64]. Non-existent antibiotic stewardship for animal health and wastewater management also contribute significantly to the spread of AMR [35, 43, 65-67].

At the population level, the accrual of risks of drugresistant infections is not readily perceived by individuals, and at the individual level, the risk of misuse of antibiotics is often overlooked in favour of the potential benefit of recovery from illnesses. For this reason, AMR is often called the "invisible threat". The AMR risk is further compounded by the lack of awareness of appropriate antibiotic usage. In 2015, a study by WHO revealed widespread antibiotic use across countries, with varying levels of understanding of the appropriate utilisation of antibiotics, and poor understanding of the potential consequences of AMR arising from the misuse of antibiotics in the majority of the respondents [68].

Antibiotics taken without prescription ranged from 9 to $62 \%$ in APAC [69]. In Indonesia, almost threequarters of respondents believe antibiotics could treat colds and flu, and in China, more than half of the respondents reported taking antibiotics in the past six months with $5 \%$ of these antibiotics purchased online. These observations are supported by other studies, including one in Australia where consumers visiting pharmacies were misinformed about the role of antibiotics in the treatment of URTIs and other ailments, with over one third believing that antibiotics would cure cold and flu faster [70]. These responses were also found to be related to the propensity for patients to self-diagnose [70].

Due to the increasing public demands for antibiotics, even in outpatient settings, the health care community in Asia increasingly prescribes antibiotics, even if inappropriate, further exacerbated by the absence or weak enforcement of policies for antibiotic stewardship [71, 72]. In Malaysia, private clinics contributed to $87 \%$ of the total quantity of antibiotics prescribed in primary care, and the bulk of the prescriptions was given unnecessarily for conditions such as URTI, acute bronchitis, acute gastroenteritis and asthma [73]. The high prescription rate of antibiotics in private clinics was attributed to the tendency for general practitioners to give in to patient's demand for antibiotics, financial incentives from the sales of the medication, and the lack of understanding of the effectiveness of antibiotics against viral infection such as URTI [73, 74]. The problem is similar in Cambodia, where village physicians, pharmacists and unofficial drug suppliers contribute to unnecessary use of antibiotics [75] due to the preference for the habitual practice of empirical therapy [76], and to compensate for poor infection control [77].

Such practices of self-medication and empirical therapy are driven mainly by poor understanding of the cause of conditions such as UTIs and the association between antibiotic use and AMR. At the same time, health systems in countries such as Singapore and Japan struggle with increasing ageing and immunocompromised populations that are more vulnerable to infections and correspondingly prescribed more antibiotics. The paradox of excessive use of antibiotics and timely access to antibiotics, however, is more prominent in LMICs. The restriction in the use and increase in access to antibiotics, without proper adaption to the local contexts, may have a detrimental effect on the control of infectious diseases and AMR [78].

\section{Public health campaign and regulatory response}

The WHO acknowledged the challenges relating to poor awareness and knowledge of AMR in the WHO Global Action Plan and is leading this front through the World Antibiotic Awareness Week that occurs in November every year [79]. In 2018, the campaign took place in almost all countries in APAC in the form of advocacy activities through mass media and outreach events, education programmes through seminars, rallies and workshops, and creative outlets such as dance competitions and art exhibitions [80].

In addition to health literacy, other socio-behavioural determinants include cultural beliefs and the use of technology. Past studies have found that Asians were more optimistic about disease risks and held stronger fatalistic beliefs about prevention than the European and Americans, potentially explaining the weaker adherence of Asians to prevention recommendations [81]. This suggests a greater need for Asian health campaigns to effectively convey the importance of preventative behaviours such as vaccinations and compliance with proper utilisation of antibiotics. In countries where information and communication technology has permeated the daily lives of its citizens, social media and online influencers are potential nodes for the dissemination of health information. Also, networks and consultations with healthcare professionals could be leveraged to promote appropriate health-seeking behaviours [82]. Such "agents of change" and platforms could be harnessed to deliver 
public health campaigns and interventions that are culturally relevant and relatable to the target populations. At this stage, many AMR campaigns are in the early phases, and few initiatives have been taken to scientifically measure and assess the effectiveness of the communication strategies. Such evaluation is essential to inform future campaigns and complement them with more indepth studies of antibiotic utilisation attitudes and behaviours amongst specific populations as well as providers in diverse settings.

The effectiveness of public health campaigns could also be augmented by policy implementation to control the use of antimicrobials where feasible. This may include introducing a requirement for a prescription to buy antibiotics, delinking the prescription and sales of antibiotics to remove financial incentives in the healthcare and food-producing sectors [83-86], and to eventually follow the lead of the European Union which has banned the use of antibiotics for animal growth promotion since 2006 [87]. The US is moving in the same direction, and China will ban the use of antimicrobials for animal growth promotion in aquaculture by 2020 [88]. However, most countries have yet to impose such regulations, and many countries are still at the stage of drafting action plans which will require political will and resources to bring them to reality.

\section{Economic analyses to strengthen the call for action against antimicrobial resistance}

The ability to estimate the financial impact of AMR is essential to justify investment for interventions, especially in LMICs where insufficient resources and competing demands exist. However, current projections of the economic impact of AMR rely greatly on simplified assumptions and data inputs due to limited data on AMR [31, 89, 90]. Many other economic studies have primarily used hospital data on direct costs for treatment, diagnosis and hospitalisation [91], limiting the study of the financial impact of AMR to the hospital setting. Even so, quantifying the excess cost of drugresistant infections in the hospital setting has proven to be difficult as the use of different methodologies in different studies has generated a broad range of excess costs ranging from hundreds to hundreds of thousands of US dollars per patient. Any projection should also be used with caution considering methodological limitations such as external validity due to the heterogeneity in caseloads, care patterns, study populations and pathogen distribution across the populations [91-93].

More importantly, hospital data does not account for the pervasive impact AMR has on society and the future. A broader assessment including the loss of productivity due to morbidity and mortality arising from AMR, loss of revenue in travel and trade due to fear of infections
[94], reduction of productivity and wellbeing due to a reluctance for high-risk medical procedures, and the financial consequence of general adverse psychological effects such as panic on the health and wellbeing of the population should be considered. The increasing prevalence of $A M R$ and possible reversion to the preantibiotic period when infectious diseases are more deadly and invasive procedures such as elective surgery are more dangerous to perform should also be factored into the calculation of the global cost of AMR [95].

\section{Box 2 Vaccination in the War Against AMR}

By reducing the need for antibiotics, vaccines may reduce the prevalence and hinder the development of resistant strains. Introduction of a conjugate pneumococcal vaccine for infants in the US in 2000 saw a $57 \%$ decline in invasive disease caused by penicillin-resistant strains and a 59\% decline in strains resistant to multiple antibiotics by 2004 across a broad age range - $81 \%$ among children under 2 years of age and $49 \%$ among persons aged 65 years and older [96]. Similarly, in Korea, the serotypes covered by the 7-valent pneumococcal conjugate vaccine (PCV7) was reported to show a 9.3\% decline in resistance to cefotaxime and $11 \%$ decline in multi-drug resistance after the introduction of the vaccine in the period 2004 to 2008, as compared to the period before between 1996 to 2003. In contrast, the serotypes not covered by PCV7 showed an increase in resistance to cefotaxime by $9.5 \%$ and multidrug resistance by $15.6 \%$ [97]. These results highlight the potential of using existing vaccines and developing new vaccines to tackle AMR. Vaccines against viruses such as influenza or dengue also have a role to play as it reduces the incidence of viral infections that are often mistakenly treated with antibiotics. So far, there have been few studies that quantify the effect of vaccines on AMR dynamics, suggesting a gap which could be filled by mathematical models to understand the impact of vaccination on the transmission of drug-resistant pathogens [98].

\section{Innovations to Fight Antimicrobial Resistance} Innovations in diagnosis and surveillance of antimicrobial resistance

The earlier section Antimicrobial Resistance Surveillance touched on the potential of technology such as WGS to understand the transmission dynamics of drug-resistant genes and pathogens and highlighted the potential for new therapeutic, diagnostic and surveillance innovations to bolster the fight against AMR.

One of the most promising areas in which technological innovations can be used to tackle AMR is to minimise empirical therapy, which has contributed to the unnecessary prescription of antibiotics for viral infections such as URTI. Among the factors promoting the practice of empirical therapy is the lack of affordable and simple point-of-care (POC) diagnostics that can distinguish bacterial from other infections and readily determine the antimicrobial susceptibility for the former. A variety of approaches to developing novel POC diagnostic tools have emerged to increase the throughput, speed, and cost-effectiveness to diagnose infectious diseases and determine the antibiotic susceptibility profile. Recent new developments include the combination of microfluidics to integrate DNA and RNA extraction, and 
PCR amplification with technologies such as microoptics to create optofluidic platforms to enable singlecell analysis and pathogen identification [99, 100]. Another success is the development of ultra-fast microfluidics-based chips that work with low number of cells for liquid-phase DNA/RNA purification and subsequent PCR amplification in a few minutes [101, 102]. These have the potential for customisation of infectious disease panels that correspond to different disease burdens in different parts of the world.

The application of engineering design principles to create affordable, fast, and accurate medical diagnostics is also gaining prominence [103-105]. This is illustrated in the application of the principles of immunochromatographic rapid diagnostic tests in over-the-counter pregnancy tests to create affordable POC diagnostics for infectious disease [103]. Given the problems of thermal denaturation and nonspecific binding events that occur with antibody-based tests, robust affinity reagents based on thermostable protein scaffolds can be complemented with systematic approaches to enhance assay sensitivity and ease-of-use [103-105].

Another potential development that could complement pathogen-specific tests is the use of systems-level "omic" analyses that profile host-derived response markers that are predictive of the infections. Initial successes in using integrated omic analyses to identify human biomarkers have been shown in studies that accurately differentiate sepsis from systemic inflammation [106], differentiate mild and severe forms of dengue infection [107], and predict host-pathogen interactions [108].

\section{Innovations in pre-clinical and regulatory science to reduce antimicrobial development costs}

In addition to diagnostics and surveillance, innovative approaches could also help to overcome the barriers in developing new drugs. The high cost of research and development and uncertainties in the return of investments have caused most large pharmaceutical companies to abandon development of new antimicrobials [109, 110], shifting the challenge to academic researchers and smaller biotechnology and pharmaceutical companies. One of the ways to reduce the cost of development is to reduce the development timeline by borrowing lessons learnt from biological therapeutics. This includes a two-pronged approach involving the multiplexing of pre-clinical and potentially clinical analytics with "omics" technologies, and dovetailing drug discovery, development, and manufacturing processes [111]. The combination of these efforts has the potential to reduce the timeline, and thus the cost, for pre-clinical development of a new antimicrobial agent from years to months. Similar innovations in manufacturing and other processes [112], as well as approaches to drug discovery such as repurposing [113], may further reduce the costs of the development phase and promote existing efforts to incentivise investments in new antimicrobials [114].

\section{Innovations in studying and manipulating the human microbiome for AMR diagnosis and treatment}

Understanding of the human microbiome as being important in the establishment of reservoirs of drugresistant pathogens is emerging $[115,116]$. The microbiome is also a potential target for novel approaches to controlling AMR [23, 117-122]. This is most apparent in the technological innovations that are advancing our understanding of the role of the human microbiome in both acquiring and combating AMR [123, 124]. These innovations are driven by the goals of not only identifying and quantifying each of the thousands of types of bacteria, bacteriophages, and other organisms in each human organ, but also of culturing and storing the isolated organisms, some of which are fastidious anaerobes.

The latter problem is being addressed by a team of scientists that founded the Global Microbiome Conservancy, which has the goal of culturing and sequencing more than 10,000 bacterial strains from the human gut in populations from more than 30 countries (http://microbiomeconservancy.org). Building on an initial collection of 7600 gut bacterial isolates and their genomes from healthy and urban North Americans, the Global Microbiome Library expanded the collection with more than 4000 additional strains from underrepresented populations in Arctic regions, and East and Central Africa. Defining the genomic sequences and the presence of AMR genes in this growing strain collection has relied on recent innovations in WGS technology, while the identification of sequences of individual microbes among the thousands in a single faecal DNA sample requires even more sophisticated sequencing innovations, such as epicPCR for profiling genetic traits such as AMR [125]. By necessity, these sequencing innovations are being matched with computational innovation for assembling and mining genomes of gut, skin, and other microbial communities, including identifying and quantifying AMR genes [126].

One of the success stories arising from innovations in microbiome science has been the use of faecal microbiome transplants (FMTs) to treat chronic, drugresistance infections by Clostridium difficile. Overgrowth of this anaerobic, sporulating, Gram-positive bacillus following the use of broad-spectrum antibiotics for treating other infections has become a major health threat in the past two decades with the emergence of a particularly virulent strain of $C$. difficile [127]. Previously treatable with a variety of antibiotics, $25 \%$ of $C$. difficile infections relapse one or more times and require multiple prolonged courses of metronidazole or vancomycin. However, FMTs have proven curative in up to $90 \%$ of 
relapsed cases in several studies [127], presumably by repopulating the gut with a "healthy" set of microbes that outcompete the $C$. difficile. This same approach can potentially be explored for AMR, with FMT as a major therapeutic tool in de-colonising intestinal carriage of drug-resistant genes and bacteria [128].

Box 3 Innovations to address AMR

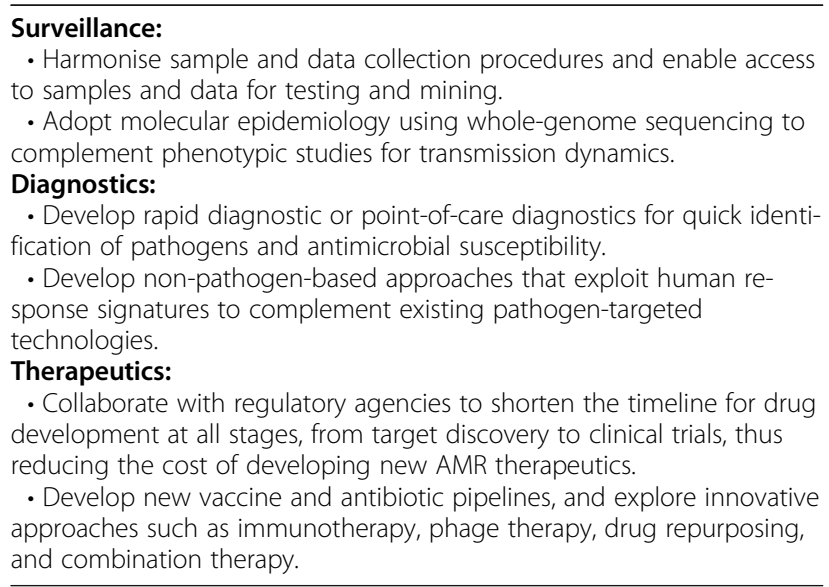

\section{Conclusion}

Three recurring themes emerge from the discussions above. The first is that there is no single solution or path to AMR control in the region, given the socioeconomic and cultural diversity within APAC, rapid changes in the region, and the multifaceted nature of the challenges of AMR. The second is the need for multisectoral and One Health approaches to synergise the efforts and harness the expertise and experiences in surveillance, sociobehavioural, economics and innovations. The third is the value of intercountry collaborations in the region and the necessity to elevate the issue of AMR control beyond just national agendas. After all, progress achieved in one country could be off-set by failures in another country. It is an opportune time to put together a regionally coordinated effort that is target-driven, sustainable, and builds on a framework that facilitates communication and consistent governance to strengthen the fight against AMR.

\section{Contribution to existing literature}

This report neither provides an extensive review of AMR in the region which has been captured exceptionally well in existing literature $[35,43]$ nor covers AMR in the context of topics such as financing and global health security. Nonetheless, it adds to existing literature the voices of people across the region who work in infectious disease control, advocacy and research. These people shared the recognition of the growing threat of AMR and the keen interest in promoting the agenda of AMR by bringing to wider attention the issues and drivers of AMR and garnering support and coordination within and beyond institutions and countries.

\begin{abstract}
Abbreviations
AMR: Antimicrobial resistance; AMU: Antimicrobial usage; APAC : Asia Pacific region; ASEAN: Association of Southeast Asian Nations; CAESAR: Central Asian and Eastern European Surveillance of Antimicrobial Resistance; CDC: Centre for Disease Control and Prevention; CRE: Carbapenem-resistant Enterobacteriaceae; EARS-Net : European Antimicrobial Resistance Surveillance Network; ESBL: Extended spectrum beta-lactamase;

ESVAC: European Surveillance of Veterinary Antimicrobial Consumption; FMTs : Faecal microbiome transplants; GLASS: Global AMR Surveillance System; LKCMedicine : Lee Kong Chian School of Medicine; LMICs: Low-and-middleincome countries; MDR- and XDR MTB: Multi-and extensively drug-resistant Mycobacterium tuberculosis; MRSA: Methicillin-resistant Staphylococcus aureus; NRL: National Reference Laboratory; OIE: World Organisation for Animal Health; PCV7: 7-valent pneumococcal conjugate vaccine; POC: Point-of-care; ReLAVRA: Red Latinoamericana de Vigilancia de la Resistencia a los Antimicrobianos; SEA: South East Asia; URTI: Upper respiratory tract infection; US: United States; WGS: Whole Genome Sequencing; WHO: World Health Organisation
\end{abstract}

\section{Acknowledgements}

This report contains the presentations and discussions at the "Antimicrobial Resistance in the Asia Pacific \& its impact on Singapore" meeting, which was made possible with the support from the organising institutions: Lee Kong Chian School of Medicine, Nanyang Technological University; Saw Swee Hock School of Public Health, National University of Singapore; SingaporeMIT Alliance for Research and Technology; National Centre for Infectious Diseases; DSO National Laboratories; and the Ministry of Health, Singapore. The authors would like to thank all speakers and panellists at the symposium: Guest of Honour Assoc Prof Benjamin ONG, Director of Medical Services, Ministry of Health, Singapore.

Speakers and Panellists:

Eric ALM, Principal Investigator, SMART Antimicrobial Resistance Interdisciplinary Research Group, Singapore; Professor of Civil and Environmental Engineering and Biological Engineering, Massachusetts Institute of Technology, USA; Associate Member, Broad Institute, USA; and Co-Director, MIT Center for Microbiome Informatics and Therapeutics, USA; Patrick BLAIR, Commanding Officer, Naval Medical Research Centre - Asia, Singapore; Peter DEDON, Lead Principal Investigator, SMART Antimicrobial Resistance Interdisciplinary Research Group, Singapore; and Singapore Professor of Biological Engineering, Massachusetts Institute of Technology, USA; Josh FRANCIS, Paediatric Infectious Diseases Specialist \& Honorary Research Fellow, Menzies School of Health Research, Australia; Thomas GONG, CEO, Star Array Pte Ltd.; and Chairman, Onsitegene Inc.; Lin Aung HTIN, Directorate, Medical Services Research Centre, Nay Pyi Taw, Myanmar; and Sir Charles Hercus Health Research Fellow, University of Otago, New Zealand; Mark JIT, Professor of Vaccine Epidemiology, London School of Hygiene and Tropical Medicine, United Kingdom; Anis KARUNIAWATI, Lecturer, Department of Microbiology, Medical Faculty, Universitas Indonesia, Indonesia; Ramanan LAXMINARAYAN, Founder and Director, Centre for Disease Dynamics, Economics \& Policy, Washington D.C., USA; and Senior Research Scholar, Princeton University, USA; Direk LIMMATHUROTSAKUL, Head of Microbiology, Mahidol Oxford Tropical Medical Research Unit, Thailand; Li Yang HSU, Clinical Director, National Centre for Infectious Diseases, Tan Tock Seng Hospital, Singapore; Vernon LEE, Director, Communicable Diseases Division, Ministry of Health, Singapore; May Oo LWIN, Associate Dean (Special Projects), College of Humanities, Arts and Social Sciences; and Professor of Communication, Wee Kim Wee School of Communication and Information, Nanyang Technological University, Singapore; Oon Tek NG, Senior Consultant, National Centre for Infectious Diseases, Tan Tock Seng Hospital, Singapore; Peter PREISER, Professor and Chair, School of Biological Sciences, College of Science, Nanyang Technological University, Singapore; Ram SASISEKHARAN, Principal Investigator, SMART Antimicrobial Resistance Interdisciplinary Research Group; and Alfred H. Caspary Professor of Biological Engineering and Health Sciences \& Technology, David H. Koch Institute for Integrative Cancer Research, Massachusetts Institute of Technology, USA; Joergen SCHLUNDT, Director, Nanyang Technological University Food Technology Centre; and Michael Fam Chair Professor of Food Science, School of Chemical and 
Biomedical Engineering, Nanyang Technological University, Singapore; Hadley SIKES, Principal Investigator, SMART Antimicrobial Resistance Interdisciplinary Research Group; and Esther and Harold E. Edgerton Associate Professor, Chemical Engineering, Massachusetts Institute of Technology, USA; Gladys Gek Yen TAN, Director, Host-pathogen Interactions Laboratory, DSO National Laboratories, Singapore; Tze Lee TAN, President, College of Family Physicians, Singapore; Paul TURNER, Director, Cambodia-Oxford Medical Research Unit, Angkor Hospital for Children, Cambodia; Annelies WILDERSMITH, Professor of Infectious Diseases, Lead for Global Health and Vaccinology, Lee Kong Chian School of Medicine, Nanyang Technological University, Singapore; Eric Peng Huat YAP, Associate Professor of Human and Microbial Genetics, Lee Kong Chian School of Medicine, Nanyang Technological University, Singapore; Tsin Wen YEO, Associate Professor of Infectious Disease, Lee Kong Chian School of Medicine, Nanyang Technological University, Singapore.

\section{Authors' contributions}

All authors contributed to the writing of the manuscript. Yam LY prepared the first draft, Wilder-Smith A and Hsu LY took the lead in writing the final draft. The content of this publication reflects the talks and discussions at the meeting titled "Antimicrobial Resistance in the Asia Pacific \& its impact on Singapore" on 13 and 14 November 2018 in Singapore. The manuscript does not necessarily reflect the views or policies of the authors' institutions. All authors read and approved the final manuscript

\section{Funding}

The expenses of the symposium and networking sessions were mainly supported by the Lee Kong Chian School of Medicine, Nanyang Technological University; Pfizer; and the British High Commission.

\section{Availability of data and materials}

No supporting data to be provided.

\section{Ethics approval and consent to participate}

Not applicable for a meeting report.

\section{Consent for publication}

All consent given for publication.

\section{Competing interests}

No conflict of interest to declare.

\section{Author details}

'Centre for Global Health, Lee Kong Chian School of Medicine, Nanyang Technological University, 11 Mandalay Road, Singapore 308232, Singapore. ${ }^{2}$ Saw Swee Hock School of Public Health, National University of Singapore, Singapore, Singapore. ${ }^{3}$ Public Health Group, Ministry of Health, Singapore, Singapore. ${ }^{4}$ Nanyang Technological University Food Technology Centre and School of Chemical and Biomedical Engineering, Nanyang Technological University, Singapore, Singapore. ${ }^{5}$ Wee Kim Wee School of Communication and Information and Lee Kong Chian School of Medicine, Nanyang Technological University, Singapore, Singapore. ${ }^{6}$ Mahidol-Oxford Tropical Medicine Research Unit, Faculty of Tropical Medicine, Mahidol University, Bangkok, Thailand. ${ }^{7}$ Centre for Tropical Medicine and Global Health, Nuffield Department of Medicine, University of Oxford, Oxford, UK. ${ }^{8}$ Department of Infectious Disease Epidemiology, Faculty of Epidemiology and Population Health, London School of Hygiene and Tropical Medicine, London, UK. ${ }^{9}$ Modelling and Economics Unit, Public Health England, London, UK.

${ }^{10}$ School of Public Health, University of Hong Kong, Hong Kong, SAR, China. ${ }^{11}$ Antimicrobial Resistance Interdisciplinary Research Group, Singapore-MIT Alliance for Research and Technology, Singapore, Singapore. ${ }^{12}$ Department of Biological Engineering, Massachusetts Institute of Technology, Cambridge, MA, USA. ${ }^{13}$ Cambodia Oxford Medical Research Unit, Angkor Hospital for Children, Siem Reap, Cambodia. ${ }^{14}$ Centre for Tropical Medicine and Global Health, Nuffield Department of Medicine, University of Oxford, Oxford, UK. ${ }^{15}$ Department of Disease Control, London School of Hygiene and Tropical Medicine, London, UK. ${ }^{16}$ Heidelberg Institute of Global Health, University of Heidelberg, Heidelberg, Germany.
Received: 20 May 2019 Accepted: 14 November 2019

Published online: 18 December 2019

\section{References}

1. Klein EY, Van Boeckel TP, Martinez EM, Pant S, Gandra S, Levin SA, et al. Global increase and geographic convergence in antibiotic consumption between 2000 and 2015. Proc Natl Acad Sci U S A. 2018;115(15):E3463-e70.

2. Summary Report on Antimicrobials Sold or Distributed for Use in FoodProducing Animals2017. Available from: https://www.fda.gov/downloads/ Forlndustry/UserFees/AnimalDrugUserFeeActADUFA/UCM628538.pdf.

3. Global Priority List Of Antibiotic-Resistant Bacteria To Guide Research, Discovery, And Development Of New Antibiotics2017. Available from: https://www.who.int/medicines/publications/global-priority-list-antibioticresistant-bacteria/en/.

4. World leaders commit to act on antimicrobial resistance: United Nations; 2016 Available from: https://www.un.org/sustainabledevelopment/blog/2 016/09/world-leaders-commit-to-act-on-antimicrobial-resistance/.

5. List of Least Developed Countries: United Nations; 2018 Available from: https://www.un.org/development/desa/dpad/wp-content/uploads/sites/45/ publication/ldc list.pdf.

6. Asia and the Pacific: United Nations; 2019. Available from: http://www.un. org/en/sections/where-we-work/asia-and-pacific/.

7. Zhou YP, Wilder-Smith A, Hsu LY. The role of international travel in the spread of methicillin-resistant Staphylococcus aureus. J Travel Med. 2014; 21(4):272-81.

8. Vila J. Multidrug-Resistant Bacteria Without Borders: Role of International Trips in the Spread of Multidrug-Resistant Bacteria. J Travel Med. 2015;22(5): 289-91.

9. Williams E, Lew TE, Fuller A, Spelman DW, Jenney AW. A case of multi-drug resistant ESBL-producing Shigella sonnei acute acalculous cholecystitis and gastroenteritis in a returned traveller. J Travel Med. 2018;25(1).

10. Hitch G, Fleming N. Antibiotic resistance in travellers' diarrhoeal disease, an external perspective. J Travel Med. 2018;25(suppl_1):S27-37.

11. Tribble DR. Resistant pathogens as causes of traveller's diarrhea globally and impact(s) on treatment failure and recommendations. J Travel Med. 2017: 24(suppl_1):S6-S12.

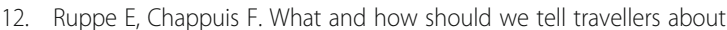
antimicrobial resistance? J Travel Med. 2017;24(2).

13. DuPont HL, Steffen R. Use of antimicrobial agents for treatment and prevention of travellers' diarrhoea in the face of enhanced risk of transient fecal carriage of multi-drug resistant enterobacteriaceae: setting the stage for consensus recommendations. J Travel Med. 2017;24(suppl_1):S57-62.

14. Doi Y, lovleva A, Bonomo RA. The ecology of extended-spectrum betalactamases (ESBLs) in the developed world. J Travel Med. 2017;24(suppl_1): S44-51.

15. Barreto Miranda I, Ignatius R, Pfuller R, Friedrich-Janicke B, Steiner F, Paland $M$, et al. High carriage rate of ESBL-producing Enterobacteriaceae at presentation and follow-up among travellers with gastrointestinal complaints returning from India and Southeast Asia. J Travel Med. 2016; 23(2):tav024.

16. Chen LH, Leder K, Barbre KA, Schlagenhauf $P$, Libman M, Keystone J, et al. Business travel-associated illness: a GeoSentinel analysis. J Travel Med. 2018; 25(1).

17. Riddle MS, Connor BA, Beeching NJ, DuPont HL, Hamer DH, Kozarsky P, et al. Guidelines for the prevention and treatment of travelers' diarrhea: a graded expert panel report. J Travel Med. 2017;24(suppl_1):S57-74.

18. McDonald LC. Effects of short- and long-course antibiotics on the lower intestinal microbiome as they relate to traveller's diarrhea. J Travel Med. 2017;24(suppl_1):S35-S8.

19. Duplessis CA, Gutierrez RL, Porter CK. Review: chronic and persistent diarrhea with a focus in the returning traveler. Trop Dis Travel Med Vaccines. 2017:3:9

20. Shlim DR, et al. J Travel Med. 2018;25(1).

21. Riddle MS, Ericsson CD, Gutierrez RL, Porter CK. Stand-by antibiotics for travellers' diarrhoea: risks, benefits and research needs. J Travel Med. 2018; 25(1)

22. Riddle MS, Connor P, Tribble DR. Antibiotics for Travellers' Diarrhoea on Trial - is there a potential role for Rifamycin SV? J Travel Med. 2018;26(1)

23. Riddle MS, Connor BA. Faecal microbiota transplantation: what is the role in travellers' diarrhoea? J Travel Med. 2018;26(1). 
24. Pommelet V, Mariani P, Basmaci R, Tourdjman M, Morin L, Gaschignard J, et al. Enteric fever among children: 50 cases in a French tertiary care centre. J Travel Med. 2018;25(1).

25. Allyn J, Angue M, Corradi L, Traversier N, Belmonte O, Belghiti M, et al. Epidemiology of 62 patients admitted to the intensive care unit after returning from Madagascar. J Travel Med. 2016;23(4).

26. Stoney RJ, Esposito DH, Kozarsky P, Hamer DH, Grobusch MP, Gkrania-

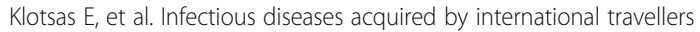
visiting the USA. J Travel Med. 2018;25(1).

27. Temkin E, Fallach N, Almagor J, Gladstone BP, Tacconelli E, Carmeli Y. Estimating the number of infections caused by antibiotic-resistant $<$ em>Escherichia coli</em> and <em>Klebsiella pneumoniae</em> in 2014: a modelling study. Lancet Glob Health. 2018;6(9):e969-e79.

28. Cassini A, Hogberg LD, Plachouras D, Quattrocchi A, Hoxha A, Simonsen GS, et al. Attributable deaths and disability-adjusted life-years caused by infections with antibiotic-resistant bacteria in the EU and the European Economic Area in 2015: a population-level modelling analysis. Lancet Infect Dis. 2019;19(1):56-66

29. Antimicrobial Resistance: Tackling a crisis for the health and wealth of nations. Review on Antimicrobial Resistance. 2014. Available from: https:// amr-review.org/sites/default/files/AMR\%20Review\%20Paper\%20-\%2 OTackling\%20a\%20crisis\%20for\%20the\%20health\%20and\%20wealth\%20of\%2 Onations_1.pdf.

30. Antimicrobial Resistance - Fact sheets on sustainable development goals: health targets2017. Available from: http://www.euro.who.int/_data/assets/ pdf_file/0005/348224/Fact-sheet-SDG-AMR-FINAL-07-09-2017.pdf?ua=1.

31. Drug Resistant Infections: A Threat to Our Economic Future2017. Available from: http://documents.worldbank.org/curated/en/323311493396993758/ pdf/114679-REVISED-v2-Drug-Resistant-Infections-Final-Report.pdf.

32. The World's Cities in 2018-Data Booklet 2018. Available from: http://www. un.org/en/events/citiesday/assets/pdf/the_worlds_cities_in_2018_data_ booklet.pdf.

33. Alirol E, Getaz L, Stoll B, Chappuis F, Loutan L. Urbanisation and infectious diseases in a globalised world. Lancet Infect Dis. 2011;11(2):131-41.

34. Kang $\mathrm{Cl}$, Song JH. Antimicrobial resistance in Asia: current epidemiology and clinical implications. Infect Chemother. 2013;45(1):22-31.

35. Chereau F, Opatowski L, Tourdjman M, Vong S. Risk assessment for antibiotic resistance in South East Asia. BMJ (Clinical research ed). 2017;358:j3393.

36. Lai CC, Lee K, Xiao Y, Ahmad N, Veeraraghavan B, Thamlikitkul V, et al. High burden of antimicrobial drug resistance in Asia. J Glob Antimicrob Resist. 2014:2(3):141-7.

37. Nordmann P, Naas T, Poirel L. Global spread of Carbapenemase-producing Enterobacteriaceae. Emerg Infect Dis. 2011;17(10):1791-8.

38. Global tuberculosis report2018. Available from: https://apps.who.int/iris/ bitstream/handle/10665/274453/9789241565646-eng.pdf?ua=1.

39. Gandra S, Tseng KK, Arora A, Bhowmik B, Robinson ML, Panigrahi B, et al. The Mortality Burden of Multidrug-resistant Pathogens in India: A Retrospective, Observational Study. Clin Infect Dis. 2018;69(4):563-70.

40. Lim C, Takahashi E, Hongsuwan M, Wuthiekanun V, Thamlikitkul V, Hinjoy S, et al. Epidemiology and burden of multidrug-resistant bacterial infection in a developing country. eLife. 2016;5.

41. Global antimicrobial resistance surveillance system (GLASS) report: early implementation 2017-2018. Available from: https:/www.who.int/glass/ resources/publications/early-implementation-report-2017-2018/en/.

42. Ashley EA, Recht J, Chua A, Dance D, Dhorda M, Thomas NV, et al. An inventory of supranational antimicrobial resistance surveillance networks involving low- and middle-income countries since 2000. J Antimic. 2018; 73(7):1737-49.

43. Zellweger RM, Carrique-Mas J, Limmathurotsakul D, Day NPJ, Thwaites GE, Baker S. A current perspective on antimicrobial resistance in Southeast Asia. J Antimicrob Chemother. 2017;72(11):2963-72.

44. Antimicrobial resistance: global report on surveillance2014. Available from: https://www.who.int/drugresistance/documents/surveillancereport/en/.

45. Om C, Daily F, Vlieghe E, McLaughlin JC, McLaws ML. "If it's a broad spectrum, it can shoot better": inappropriate antibiotic prescribing in Cambodia. Antimicrob Resist Infect Control. 2016:5:58.

46. Teerawattanasook N, Tauran PM, Teparrukkul P, Wuthiekanun V, Dance DAB, Arif M, et al. Capacity and Utilization of Blood Culture in Two Referral Hospitals in Indonesia and Thailand. Am J Trop Med Hyg. 2017;97(4):1257-61.

47. Ashley EA, Dance DAB, Turner P. Grading antimicrobial susceptibility data quality: room for improvement. Lancet Infect Dis. 2018;18(6):603-4.
48. Turner $P$, Fox-Lewis A, Shrestha P, Dance DAB, Wangrangsimakul T, Cusack T-P, et al. Microbiology Investigation Criteria for Reporting Objectively (MICRO): a framework for the reporting and interpretation of clinical microbiology data. BMC Med. 2019;17(1):70.

49. Tebano G, la Martire G, Sarmento N, Francis JR. Antibiotic resistance in Timor-Leste: a systematic review of evidence. J Antimicrob Chemother 2018. 73(4):1110-1.

50. Marr I, Sarmento N, O'Brien M, Lee K, Gusmao C, de Castro G, et al. Antimicrobial resistance in urine and skin isolates in Timor-Leste. J Glob Antimicrob Resist. 2018;13:135-8.

51. Parathon $H$, Kuntaman $K$, Widiastoety TH, Muliawan BT, Karuniawati A, Qibtiyah $\mathrm{M}$, et al. Progress towards antimicrobial resistance containment and control in Indonesia. BMJ (Clinical research ed). 2017:358:3808.

52. South East Asia: The Fleming Fund; 2018 Available from: https://www. flemingfund.org/regions/south-east-asia/.

53. AutoMated tool for Antimicrobial resistance Surveillance System (AMASS) figshare2019 Available from: https://figshare.com/articles/AMASS zip/ 7763330/2.

54. Chung The H, Karkey A, Pham Thanh D, Boinett CJ, Cain AK, Ellington M, et al. A high-resolution genomic analysis of multidrug-resistant hospital outbreaks of Klebsiella pneumoniae. EMBO Mol Med. 2015;7(3):227-39.

55. The HC, Thanh DP, Holt KE, Thomson NR, Baker S. The genomic signatures of Shigella evolution, adaptation and geographical spread. Nat Rev Microbiol. 2016;14(4):235-50.

56. Falagas ME, Tansarli GS, Karageorgopoulos DE, Vardakas KZ. Deaths attributable to carbapenem-resistant Enterobacteriaceae infections. Emerg Infect Dis. 2014;20(7):1170-5

57. Marimuthu K, Venkatachalam I, Khong WX, Koh TH, Cherng BPZ, Van La M, et al. Clinical and Molecular Epidemiology of Carbapenem-Resistant Enterobacteriaceae Among Adult Inpatients in Singapore. Clin Infect Dis. 2017;64(suppl_2):S68-s75.

58. Nkengasong JN, Maiyegun O, Moeti M. Establishing the Africa Centres for Disease Control and Prevention: responding to Africa's health threats. Lancet Glob Health. 2017:5(3):e246-e7.

59. African Countries Launch Framework To Tackle The Threat Of Antibiotic Resistant Infections: Africa Centres for Disease Control and Prevention; 2017 [Available from: http://www.africacdc.org/press-centre/news/30-africancountries-launch-framework-to-tackle-the-threat-of-antibiotic-resistantinfections.

60. Consumption of antimicrobial agents in Thailand in 2017. Available from: http://ihppthaigov.net/DB/publication/attachresearch/421/chapter1.pdf.

61. Van Boeckel TP, Brower C, Gilbert M, Grenfell BT, Levin SA, Robinson TP, et al. Global trends in antimicrobial use in food animals. Proc Natl Acad Sci U S A. 2015;112(18):5649-54

62. Current prices of antibiotics by class, age: The Center For Disease Dynamics, Economics \& Policy; Available from: https://cddep.org/tool/current_prices_ antibiotics_class_age/.

63. Glaesser D, Kester J, Paulose H, Alizadeh A, Valentin B. Global travel patterns: an overview. J Travel Med. 2017;24(4).

64. Frost I, Van Boeckel TP, Pires J, Craig J, Laxminarayan R. Global geographic trends in antimicrobial resistance: the role of international travel. J Travel Med. 2019.

65. Holloway KA, Kotwani A, Batmanabane G, Puri M, Tisocki K. Antibiotic use in South East Asia and policies to promote appropriate use: reports from country situational analyses. BMJ (Clinical research ed). 2017;358:j2291.

66. Medicines use in primary care in developing and transitional countries:factbook summarising results from studies reported between 1990 and 2006. Available from: https://www.who.int/medicines/publications/who_emp_2009.3/en/.

67. Holloway KA vDL. The World Medicines Situation. Rational use of medicines [Internet]. 2011. Available from: http://apps.who.int/medicinedocs/ documents/s20054en/s20054en.pdf?ua=1.

68. WHO. Multi-country survey reveals widespread public misunderstanding about antibiotic resistance. Geneva: World Health Organisation; 2015. Available from: https://www.who.int/news-room/detail/16-11-2015-who-multi-country-surveyreveals-widespread-public-misunderstanding-about-antibiotic-resistance

69. Morgan DJ, Okeke IN, Laxminarayan R, Perencevich EN, Weisenberg S. Nonprescription antimicrobial use worldwide: a systematic review. Lancet Infect Dis. 2011;11(9):692-701.

70. Fredericks I, Hollingworth S, Pudmenzky A, Rossato L, Syed S, Kairuz T. Consumer knowledge and perceptions about antibiotics and upper respiratory tract infections in a community pharmacy. Int J Clin Pharm. 2015;37(6):1213-21. 
71. Nepal G, Bhatta S. Self-medication with Antibiotics in WHO Southeast Asian Region: A Systematic Review. Cureus. 2018;10(4):e2428.

72. Baker JA. A health issue for the future? Pharmaceutical Society of Singapore raises alarm on antibiotic resistance: Channel News Asia; 2018 Available from: https://www.channelnewsasia.com/news/singapore/prescribingantibiotics-for-colds-fever-sore-throat-runny-nose-10933828.

73. Ab Rahman N, Teng CL, Sivasampu S. Antibiotic prescribing in public and private practice: a cross-sectional study in primary care clinics in Malaysia. BMC Infect Dis. 2016:16:208.

74. Hassali MA, Kamil TKT, Md Yusof FA, Alrasheedy AA, Yusoff ZM, Saleem F, et al. General practitioners' knowledge, attitude and prescribing of antibiotics for upper respiratory tract infections in Selangor, Malaysia: findings and implications. Expert Rev Anti-Infect Ther. 2015;13(4):511-20.

75. Om C, Daily F, Vlieghe E, McLaughlin JC, McLaws ML. Pervasive antibiotic misuse in the Cambodian community: antibiotic-seeking behaviour with unrestricted access. Antimicrob Resist Infect Control. 2017;6:30.

76. Om C, McLaws ML, Vlieghe E, Daily F, McLaughlin JC. Cambodia: the first national study of antibiotic prescribing and resistance using mixed methods approach. Antimicrob Resist Infect Control. 2015;4(Suppl 1) P183-P.

77. Handley E. Antibiotics prescribed 'blindly', doctors admit Cambodia: Phnom Penh Post; 2016 Available from: https://www.phnompenhpost.com/ national/antibiotics-prescribed-blindly-doctors-admit.

78. Mendelson M, Røttingen J-A, Gopinathan U, Hamer DH, Wertheim H, Basnyat $B$, et al. Maximising access to achieve appropriate human antimicrobial use in low-income and middle-income countries. Lancet. 2016;387(10014):188-98.

79. Global action plan on antimicrobial resistance2015. Available from: http:// www.who.int/iris/handle/10665/193736.

80. Geneva, Switzerland: World Health Organisation; WAAW Global Campaign. Available from: http://apps.who.int/world-antibiotic-awareness-week/ activities/en\#/grid-content.

81. Kim HK, Lwin MO. Cultural Effects on Cancer Prevention Behaviors: Fatalistic Cancer Beliefs and Risk Optimism Among Asians in Singapore. Health Commun. 2017;32(10):1201-9.

82. Lwin MO. Examining psychosocial determinents of influenza and vaccine uptake intentions in Singapore: Initial findings. In: Thematic monthly research meeting on Vaccine Preventable Diseases. Singapore: Institute of Infectious Diseases and Epidemiology (IID); 2017.

83. Speksnijder DC, Mevius DJ, Bruschke CJ, Wagenaar JA. Reduction of veterinary antimicrobial use in the Netherlands. The Dutch success model. Zoonoses Public Health. 2015;62(Suppl 1):79-87.

84. National Strategic Action Plan on Antimicrobial Resistance2017. Available from: https://www.moh.gov.sg/content/dam/moh_web/Publications/ Information\%20Papers/SG\%20National\%20Strategic\%20Action\%20Plan\%2 0on\%20AMR.pdf.

85. Australia's First National Antimicrobial Resistance Strategy 2015-2019. Available from: https://www.amr.gov.au/resources/national-amr-strategy.

86. Swedish strategy to combat antibiotic resistance 2016. Available from: https://www.government.se/contentassets/168838e186de455ca7fe868bee92 d209/swedish-strategy-to-combat-antibiotic-resistance.pdf.

87. Ban on antibiotics as growth promoters in animal feed enters into effect: European Commission; 2005. Available from: http://europa.eu/rapid/pressrelease_IP-05-1687_en.htm.

88. Xiaodong W. Use of antibiotics in poultry and livestock to be reduced: China Daily; 2017. Available from: http://www.chinadaily.com.cn/china/201706/24/content_29869315.htm.

89. Taylor J, Hafner M, Yerushalmi E, Smith R, Bellasio J, Vardavas R, BienkowskaGibbs T, Rubin J. Estimating the economic costs of antimicrobial resistance: Model and Results. United Kingdom; 2014. Available from: https://www. rand.org/pubs/research_reports/RR911.html

90. The global economic impact of anti-microbial resistance 2014. Available from: https://home.kpmg/content/dam/kpmg/pdf/2014/12/amr-report-final.pdf.

91. Gandra S, Barter DM, Laxminarayan R. Economic burden of antibiotic resistance: how much do we really know? Clin Microbiol Infect. 2014;20(10): 973-80

92. Cohen B, Larson EL, Stone PW, Neidell M, Glied SA. Factors associated with variation in estimates of the cost of resistant infections. Med Care. 2010; 48(9):767-75.

93. Naylor NR, Atun R, Zhu N, Kulasabanathan K, Silva S, Chatterjee A, et al. Estimating the burden of antimicrobial resistance: a systematic literature review. Antimicrob Resist Infect Control. 2018;7:58.
94. Smith RD, Yago M, Millar M, Coast J. Assessing the macroeconomic impact of a healthcare problem: The application of computable general equilibrium analysis to antimicrobial resistance. J Health Econ. 2005;24(6):1055-75.

95. Smith $\mathrm{R}$, Coast J. The true cost of antimicrobial resistance. BMJ (Clinical research ed). 2013;346:f1493.

96. Kyaw MH, Lynfield R, Schaffner W, Craig AS, Hadler J, Reingold A, et al. Effect of Introduction of the Pneumococcal Conjugate Vaccine on DrugResistant Streptococcus pneumoniae. N Engl J Med. 2006;354(14):1455-63.

97. Lee S, Bae S, Lee K-J, Yu J-Y, Kang Y. Changes in serotype prevalence and antimicrobial resistance among invasive Streptococcus pneumoniae isolates in Korea, 1996-2008. J Med Microbiol. 2013:62(8):1204-10.

98. Atkins KE, Lafferty El, Deeny SR, Davies NG, Robotham JV, Jit M. Use of mathematical modelling to assess the impact of vaccines on antibiotic resistance. Lancet Infect Dis. 2018;18(6):e204-e13.

99. Liu PY, Chin LK, Ser W, Ayi TC, Yap PH, Bourouina T, et al. An optofluidic imaging system to measure the biophysical signature of single waterborne bacteria. Lab Chip. 2014;14(21):4237-43.

100. Yu JQ, Huang W, Chin LK, Lei L, Lin ZP, Ser W, et al. Droplet optofluidic imaging for lambda-bacteriophage detection via co-culture with host cell Escherichia coli. Lab Chip. 2014;14(18):3519-24.

101. About Us - Star Array: Star Array Pte Ltd; 2017 Available from: https://www. star-array.com.

102. About Us - Onsite Gene: OnsiteGene Inc.; 2017 Available from: https://www. onsitegene.com

103. Miller E, Sikes HD. Addressing Barriers to the Development and Adoption of Rapid Diagnostic Tests in Global Health. Nanobiomedicine. 2015;2.

104. Miller EA. Jabbour Al Maalouf Y, Sikes HD. Design Principles for Enhancing Sensitivity in Paper-Based Diagnostics via Large-Volume Processing. Anal Chem. 2018;90(15):9472-9.

105. Miller EA, Baniya S, Osorio D, Al Maalouf YJ, Sikes HD. Paper-based diagnostics in the antigen-depletion regime: High-density immobilization of rcSso7d-cellulose-binding domain fusion proteins for efficient target capture. Biosens Bioelectron. 2018;102:456-63.

106. Langley RJ, Tipper JL, Bruse S, Baron RM, Tsalik EL, Huntley J, et al. Integrative "omic" analysis of experimental bacteremia identifies a metabolic signature that distinguishes human sepsis from systemic inflammatory response syndromes. Am J Respir Crit Care Med. 2014;190(4):445-55.

107. Cui L, Lee $Y H$, Thein TL, Fang J, Pang J, Ooi EE, et al. Serum Metabolomics Reveals Serotonin as a Predictor of Severe Dengue in the Early Phase of Dengue Fever. PLoS Negl Trop Dis. 2016;10(4):e0004607.

108. Jean Beltran PM, Federspiel JD, Sheng X, Cristea IM. Proteomics and integrative omic approaches for understanding host-pathogen interactions and infectious diseases. Mol Syst Biol. 2017;13(3):922.

109. Rex JH, Eisenstein Bl, Alder J, Goldberger M, Meyer R, Dane A, et al. A comprehensive regulatory framework to address the unmet need for new antibacterial treatments. Lancet Infect Dis. 2013;13(3):269-75.

110. Spellberg B. The future of antibiotics. Crit Care. 2014;18(3):228.

111. Revolutionizing Rapid Responses to Infectious Disease: Tychan Pte. Ltd; 2019 [Available from: https://www.tychan.com.

112. Fisher AC, Kamga MH, Agarabi C, Brorson K, Lee SL, Yoon S. The Current Scientific and Regulatory Landscape in Advancing Integrated Continuous Biopharmaceutical Manufacturing. Trends Biotechnol. 2019;37(3):253-67.

113. Miro-Canturri A, Ayerbe-Algaba R, Smani Y. Drug Repurposing for the Treatment of Bacterial and Fungal Infections. Front Microbiol. 2019;10:41.

114. Simpkin VL, Renwick MJ, Kelly R, Mossialos E. Incentivising innovation in antibiotic drug discovery and development: progress, challenges and next steps. J Antibiot (Tokyo). 2017;70(12):1087-96.

115. Jiang $X$, Hall AB, Arthur TD, Plichta DR, Covington $C T$, Poyet $M$, et al. Invertible promoters mediate bacterial phase variation, antibiotic resistance, and host adaptation in the gut. Science (New York, NY). 2019;363(6423):181-7.

116. Brinkac L, Voorhies A, Gomez A, Nelson KE. The Threat of Antimicrobial Resistance on the Human Microbiome. Microb Ecol. 2017;74(4):1001-8.

117. Smillie CS, Sauk J, Gevers D, Friedman J, Sung J, Youngster I, et al. Strain Tracking Reveals the Determinants of Bacterial Engraftment in the Human Gut Following Fecal Microbiota Transplantation. Cell Host Microbe. 2018; 23(2):229-40.e5

118. Pakpour S, Bhanvadia A, Zhu R, Amarnani A, Gibbons SM, Gurry T, et al. Identifying predictive features of Clostridium difficile infection recurrence before, during, and after primary antibiotic treatment. Microbiome. 2017;5(1):148.

119. Kim S, Covington A, Pamer EG. The intestinal microbiota: Antibiotics, colonization resistance, and enteric pathogens. Immunol Rev. 2017;279(1):90-105. 
120. DuPont HL, Steffen R. Use of antimicrobial agents for treatment and prevention of travellers' diarrhoea in the face of enhanced risk of transient fecal carriage of multi-drug resistant enterobacteriaceae: setting the stage for consensus recommendations. J Travel Med. 2016;23(6).

121. Rasko DA. Changes in microbiome during and after travellers' diarrhea: what we know and what we do not. J Travel Med. 2017;24(suppl_1):S52-S6.

122. McDonald LC. Effects of short- and long-course antibiotics on the lower intestinal microbiome as they relate to traveller's diarrhea. J Travel Med. 2017;24(suppl_1):S35-S8.

123. Welcome to OPENBIOME United States. Available from: https://www. openbiome.org.

124. Finch United States. Available from: https://finchtherapeutics.com.

125. Spencer SJ, Tamminen MV, Preheim SP, Guo MT, Briggs AW, Brito IL, et al. Massively parallel sequencing of single cells by epicPCR links functional genes with phylogenetic markers. ISME J. 2016;10(2):427-36.

126. Malla MA, Dubey A, Kumar A, Yadav S, Hashem A, Abd Allah EF. Exploring the Human Microbiome: The Potential Future Role of Next-Generation Sequencing in Disease Diagnosis and Treatment. Front Immunol. 2018;9:2868.

127. Collins J, Auchtung JM. Control of Clostridium difficile Infection by Defined Microbial Communities. Microbiol Spectr. 2017;5(5)

128. Relman DA, Lipsitch M. Microbiome as a tool and a target in the effort to address antimicrobial resistance. Proc Natl Acad Sci U S A. 2018;115(51):12902-10.

\section{Publisher's Note}

Springer Nature remains neutral with regard to jurisdictional claims in published maps and institutional affiliations.

Ready to submit your research? Choose BMC and benefit from:

- fast, convenient online submission

- thorough peer review by experienced researchers in your field

- rapid publication on acceptance

- support for research data, including large and complex data types

- gold Open Access which fosters wider collaboration and increased citations

- maximum visibility for your research: over $100 \mathrm{M}$ website views per year

At BMC, research is always in progress.

Learn more biomedcentral.com/submissions 